\title{
Servant Leadership and Voice Behavior: Organizational Identification as a Mediator
}

\author{
Qing Tian, Yanli Hu and Kongtong Cheng \\ School of Business, Macau University of Science and Technology, Macau, China
}

\begin{abstract}
To conduct a survey with 68 supervisors (85\% response rate) and 463 subordinates (with $82.68 \%$ response rate) in 68 work units in tourism industry across multiple organizations, by using "supervisor and subordinate" questionnaire with convenience sampling and stratified sampling to get data. Using Smart PLS 3 to conduct data analysis and statistical result support for our hypothesized models that (1) servant leadership is positively related to voice behavior, (2) organizational identification can mediate the relationship between servant leadership and voice behavior. In the later, we discuss the theoretical and practical implications of these findings, and provide limitations and suggestions for the future study.
\end{abstract}

\section{Keywords—servant leadership; self-efficacy; voice behavior}

\section{INTRODUCTION}

Nowadays, faced with the increasingly complex organizational environment, employees' opinions and suggestions are considered to improve the quality of decision-making and promote the whole performance of organization so as to adapt to the key competition and organizational success factors. Voice behavior refers to "expression of constructive challenge with intent to improve rather than merely to criticize" (Van Dyne \& LePine, 1998, p. $109)^{[1]}$. Compared with other leadership theories, servant leadership might be a more substantial theory for explaining employee voice behaviors. Servant leadership, "begins with the natural feeling that one wants to serve, to serve first. Then conscious choice brings one to aspire to lead'"(Greenleaf, $1970 / 1991$ p. 7) ${ }^{[2]}$. Each case of voice behavior is distinctive and unique (Miceli, 2004) ( $^{[3]}$ and the actions taken by those said to be speaker are driven by various psychological factors (Gobert \& Punch, 2000) $)^{[4]}$, which need to explore for understanding how individual's psychological changing would result in voice. Thus, this paper considers servant leadership to explore its impact on voice behavior, and find out the mediation effect of organizational identification between them.

\section{THEORETICAL HYPOTHESIS}

Voice may enhance employees' feelings of control, which has been shown to increase satisfaction and motivation and decrease stress (Greenberger \& Strasser, 1986) ${ }^{[5]}$. Voice may lead to relatively positive attitudes because of the benefits associated with being able to express one's views and concerns (Morrison \& Milliken, 2000) ${ }^{[6]}$. In social exchange theory, human relations are formed through the use of subjective cost benefit analysis and comparative substitution. This theory is rooted in economics, psychology and sociology. Social exchange theory has many main assumptions of rational choice theory and structuralism. It is also often used in the commercial world to suggest a bilateral, interrelated and valuable process, including transactions or simple exchanges. The integrity of servant leaders and their concern for others enhance their attractiveness, and so do servant leaders' trust in others. When followers think servant leader is other-focused, they aspire to return the leader and thus provide more useful ideas to leader. Servant leader provides situational cues to influence employee attitudes and behaviors. On the basis of this reasoning, we propose the following:

Hypothesis 1: servant leadership is positively related to voice behavior

Organizational identification (OID) is defined as a perceived oneness with an organization and the experience of the organization s successes and failures as one's own (Mael F, Ashforth B E.1992) $)^{[7]}$. Organizational identification has been defined as "perceived oneness with an organization and the experience of the organization's success or failures as one's own" (Mael and Ashforth, 1992, p. 103) ${ }^{[7]}$. Servant leaders are proactive (Bande et al., 2016) ${ }^{[8]}$, such leaders to increase cooperation (Dukerich, Golden, \& Shortell, 2002) ${ }^{[9]}$, altruistic calling, emotional healing, persuasive mapping, wisdom, and organizational stewardship (Barbuto J E, Wheeler D W. 2006) ${ }^{[10]}$, influencing others through building trusting relationships (Beck C D. 2014) ${ }^{[11]}$, fulfilling employees' three basic psychological needs, namely for autonomy, competence and relatedness (Chiniara et al., 2016) ${ }^{[12]}$, stressing personal integrity and serving others(Liden et al. 2008) ${ }^{[13]}$, which, in turn, should promote employees' organizational identification. The servant leader make subordinates gain more development and trusty environment in the organization, they would devote themselves to do better for the leader by providing useful suggestions to them.

Hypothesis 2: Organizational identification mediates the relationship between servant leadership and voice behavior. 


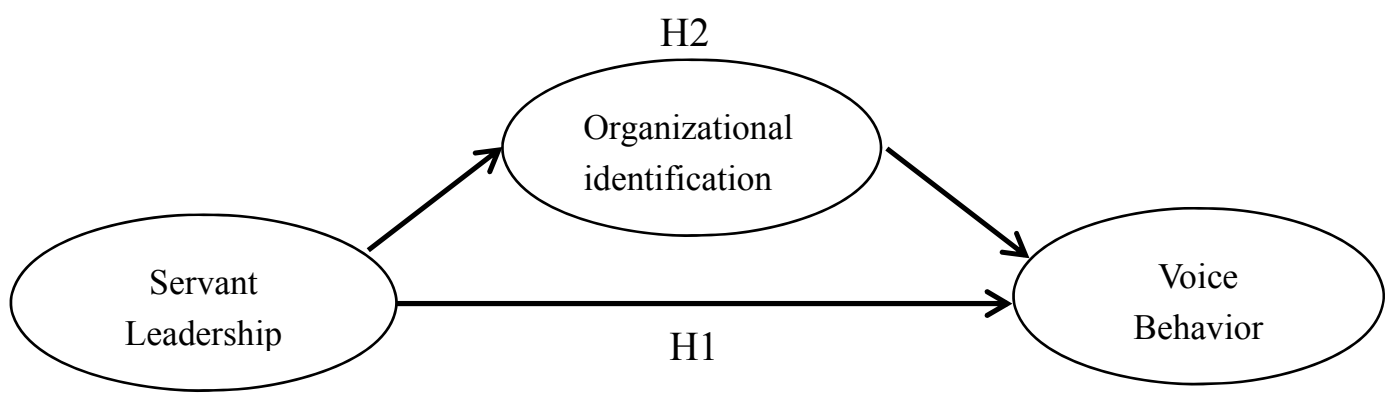

FIGURE I. RESEARCH MODEL

\section{Methodology}

We distributed 80 supervisor questionnaires and 560 subordinate questionnaires And we received the 68 valid supervisor questionnaire (85\% response rate) and 463 valid subordinate questionnaires $(82.68 \%$ response rate) during June 1st, 2017 and January 10th, 2018. We adopted both convenience sampling and stratified sampling to distribute the questionnaires. Moreover, we adopt two times to collect our questionnaires. We firstly distributed servant leadership and organization identification questionnaires. Two weeks later, voice behavior questionnaire was distributed. In the valid supervisor questionnaires, the number of male was $43(63.2 \%)$, while female had a number of $25(36.8 \%)$. In the valid subordinate questionnaires, the number of male was $239(51.6 \%)$, while female had a number of 224(48.4\%). For the corporation scale, the number of company whose scale bellowed 50 was $7(10.3 \%)$ and whose scale between 101 and 300 was $35 \%$, while the company scale over 500 reached $26.3 \%$. and there was only 2 organizations between the size frome 51 to 100 , occupying $2.9 \%$, while there was only 9 organizations between which the size is from 101 to 300 , reaching $13.2 \%$.

\section{MEASURES}

Even though the questionnaires were in Chinese, the item scales were originally written in English. In order to keep accurate translation, we used conventional method of back translation (Brislin, 1980) ${ }^{[14]}$ to translate the item into Chinese and then back into English, which can help respondent to be more easier to understand. All items were measured ranging from 1 'strongly agree' to 5 'strongly disagree' by Likert-five-point Scale. Regarding Servant leadership, this study used the 10-item Servant Leadership Scale (SLS) developed by Ehrhart, M. G. (2004) ${ }^{[15]}$. Sample item are "My department manager spends the time to form quality relationships with department employees" The Cronbach's alpha for this scale was 0.96. Regarding voice behavior, this study used a 5-item scale developed by Rusbult, C. E., Farrell, D., Rogers, G., \& Mainous, A. G., III. (1988) ${ }^{[16]}$. Sample items like, "(this employee) would ask me to discuss the problem", The Cronbach's alpha for this scale was 0.83. Regarding organizational identification, this study used 5-point organizational identification developed by Mael, F., \& Ashforth, B. E. (1992) $)^{[7]}$. Items were as following, including "When someone criticizes (name of organization), it feels like a personal insult", The Cronbach's alpha was 0.95 .

\section{DATA ANALYSIS}

The statistical result would be following. Table 1, it can be seen that the coefficient between servant leadership and voice behavior was $0.13^{* *}$, the coefficient between servant leadership and organizational identification was $0.26^{* *}$, the coefficient between organizational identification and voice behavior was $0.46^{* *}$.

Table 2 shows that ethical climate mediate the relationship between ethical leadership and moral efficacy. In model $1, \beta=$ $0.244(\mathrm{P}<0.001), \triangle \mathrm{R} 2=0.089(\mathrm{p}<0.001)$, which supported hypothesis 1 that servant leadership was positively impacting on voice behavior. In model 2 , in the direct effect, the $\beta$ of servant leadership on voice behavior was $0.29 * * * \quad(\mathrm{P}<0.001)$. Taking organizational identification into consideration, in the indirect effect, the $\beta$ of servant leadership on voice behavior was $-0.00(0.22)$, but the organizational identification on voice behavior was $0.50 * * *(\mathrm{P}<0.001)$, which support hypothesis 2 .

TABLE I. MEANS, STANDARD DEVIATION, AND CORRELATIONS

\begin{tabular}{cccccccccc}
\hline & Mean & S.D. & Gndr1 & Gndr2 & Age1 & Age2 & SL & OI & VB \\
\hline Gndr1 & 0.48 & 0.50 & 1 & & & & & & \\
Gndr2 & 0.35 & 0.48 & $0.11^{*}$ & 1 & & & & \\
Age 1 & 1.65 & 0.76 & -0.07 & $-0.16^{* *}$ & 1 & & & & \\
Age 2 & 2.35 & 0.77 & -0.03 & $-0.18^{* *}$ & $0.24^{* *}$ & 1 & & & \\
SL & 3.51 & 0.68 & 0.06 & 0.06 & -0.07 & -0.04 & 1 & & \\
OI & 3.87 & 0.64 & $0.11^{*}$ & 0.05 & -0.07 & -0.03 & $0.26^{* *}$ & 1 & \\
VB & 3.59 & 0.74 & -0.02 & -0.03 & 0.03 & $0.10^{*}$ & $0.13^{* *}$ & $0.46^{* *}$ & 1 \\
\hline
\end{tabular}


TABLE II. DIRECT, INDIRECT, INTERACTION EFFECT AND TOTAL EFFECTS

\begin{tabular}{lllrr}
\hline & Effect on voice behavior & Direct effect & Indirect effect & Total effect \\
\hline Model 1 & Servant leadership(R2 $=0.02)$ & & $0.15^{* *}(2.85)$ \\
\hline Effect on mediator/criterion & & \\
\hline Model 2 & The mediated model explaining voice behavior & & \\
& Organizational identification(R2=0.09) & & \\
$\quad$ Servant leadership & $0.29^{* * *}(6.37)$ & & \\
& Voice behavior (R2=0.24) & & \\
$\quad$ Servant leadership & $-0.00(0.22)$ & $0.15^{* * *}(5.31)$ & \\
Organizational identification & $0.50^{* * *}(10.31)$ & & \\
&
\end{tabular}

$* \mathrm{P}<0.05, * * \mathrm{P}<0.01$, The indirect effect and $\mathrm{t}-\mathrm{values}$ were using the bootstrapping procedure $(\mathrm{N}=463)$

\section{THEORETICAL AND MANAGERIAL IMPLICATION}

This research is one of the first to explore the voice behavior by considering servant leadership as an antecedent to motivate individuals to speak up, which is greatly neglect by previous research. Servant leaders concentrate on developing employees in the areas of task effectiveness, community stewardship, self-motivation, and future leadership capabilities (Greenleaf 1970) ${ }^{[2]}$ to help employees to give some valuable and insight suggestions. It can be a good suggestion to develop other-focused leader in the organization, then to receive appreciated voice from employees to improving organizational performance. In the second, managers should be encouraged to engage in servant leadership, which can create a working culture, not only to increase the voice of the followers to the leaders, but also to promote the identity of the followers and the values and confidence of the group to stabilize the organization. Employees usually have the right to speak and take personal costs. In this study, we show when (and why) sounds are dangerous to those who speak, by paying attention to whether the servant leadership is concerned about the interests of the staff and putting the priorities of the employees in the first place.

\section{LIMITATION AND FUTURE RESEARCH DIRECTIONS}

In the first, one weakness of our study was the cross-sectional design, which precludes our ability to make causal inferences. For example, it is possible that individual employee behaviors influenced culture perceptions, which in turn encouraged leaders to reinforce the culture with continued voice in servant leader behaviors. In the second, longitudinal research is necessary to ascertain the validity of our contentions regarding the causal relations among the variables. It is therefore important that longitudinal studies on the effects of group voice climate be conducted in the future. Last but not least, further research can base on our research model to investigate the moderate role of hierarchical rank in leader, which may lead to a different level of voice behavior.

\section{REFERENCES}

[1] Van Dyne, L., \& Lepine, J. A. (1998). Helping and voice extra-role behaviors: evidence of construct and predictive validity. Academy of Management Journal, 41(1), 108-119.

[2] Greenleaf, R.K. 1970. The servant as leader. Newton Centre, MA: The Robert K. Greenleaf Center.
[3] Miceli, M. P. (2004). Whistle-blowing research and the insider: lessons learned and yet to be learned. Journal of Management Inquiry, 13(4), 364-366.

[4] Gobert, J., \& Punch, M. (2000). Whistleblowers, the public interest, and the public interest disclosure act 1998. Modern Law Review, 63(1), $25-54$.

[5] Greenberger, D. B., \& Strasser, S. (1986). Development and application of a model of personal control in organizations. Academy of Management Review, 11(1), 164-177

[6] Morrison, E. W., \& Milliken, F. J. (2000). Organizational silence: a barrier to change and development in a pluralistic world. Academy of Management Review, 25(4), 706-725.

[7] Mael, F., \& Ashforth, B. E. (1992). Alumni and their alma mater: a partial test of the reformulated model of organizational identification. Journal of Organizational Behavior, 13(2), 103-123.

[8] Bande, B., Fernándezferrín, P., Varelaneira, C., \& Oteroneira, C. (2016). Exploring the relationship among servant leadership, intrinsic motivation and performance in an industrial sales setting. Journal of Business \& Industrial Marketing, 31(2).

[9] Dukerich, J. M., Golden, B. R., \& Shortell, S. M. (2002). Beauty is in the eye of the beholder: the impact of organizational identification, identity, and image on the cooperative behaviors of physicians. Administrative Science Quarterly, 47(3), 507-533.

[10] Barbuto, J. E., \& Wheeler, D. W. (2006). Scale development and construct clarification of servant leadership. Group \& Organization Management An International Journal, 31(3), 300-326.

[11] Beck, C. D. (2014). Antecedents of servant leadership. Journal of Leadership \& Organizational Studies, 21(3), 299-314.

[12] Chiniara, M., \& Bentein, K. (2016). Linking servant leadership to individual performance: differentiating the mediating role of autonomy, competence and relatedness need satisfaction. Leadership Quarterly, 27(1), 124-141.

[13] Liden, R. C., Wayne, S. J., Zhao, H., \& Henderson, D. (2008). Servant leadership: development of a multidimensional measure and multi-level assessment. Leadership Quarterly, 19(2), 161-177.

[14] Brislin, R. W. (1980). Translation and content analysis of oral and written material. 389-444.

[15] Ehrhart, M. G. (2004). Leadership and procedural justice climate as antecedents of unit - level organizational citizenship behavior. Personnel Psychology, 57(1), 61-94.

[16] Rusbult, C. E., Farrell, D., Rogers, G., \& Mainous, A. G., III. (1988). Impact of exchange variables on exit, voice, loyalty, and neglect: An integrative model of responses to declining job satisfaction. Academy of Management Journal, 31, 599-627. 